\title{
Pengaruh Pelayanan Berbasis Teknologi Informasi Listrik Prabayar dan Kerelasian Pelanggan terhadap Kepercayaan Pelanggan dan Dampaknya pada Citra Perusahaan
}

\author{
(Suatu Survey pada Pelayanan Pelanggan Listrik di Kalimantan Barat) \\ FAJAR SUROYO \\ Program Doktor Manajemen Bisnis Universitas Padjadjaran, Bandung, Indonesia \\ Email Korespondensi: it.admin@dmb.fe.unpad.ac.id
}

\begin{abstract}
Abstrak
Pelayanan teknologi informasi Listrik Prabayar (LPB) dan Kerelasian Pelanggan yang sudah dan sedang dilaksanakan oleh PLN diteliti dalam penelitian ini apakah menambah rasa kepercayaan pelanggan pada jasa PLN yang dapat berperngaruh terhadap peningkatan citra perusahaan. Penelitian menggunakan survei yang dilakukan terhadap 250 pelanggan listrik prabayar di provinsi Kalimantan Barat. Hasil penelitian dengan menggunakan pendekatan analisis deskriptif didapatkan bahwa pelayanan teknologi informasi pelanggan dan kerelasian pelanggan terhadap kepercayaan pelanggan dan citra perusahaan menurut pelanggan adalah sudah baik. Sedangkan pendekatan analisis verifikatif didapatkan bahwa dengan pemakaian teknologi informasi yang semakin berkembang pesat dalam mendukung pelayanan pelanggan akan sangat membantu peningkatan rasa percaya pelanggan terhadap produk perusahaan sehingga berdampak pada Citra perusahaan yang meningkat.
\end{abstract}

Kata Kunci: Pelayanan, teknologi informasi listrik, kerelasian pelanggan, citra perusahaan

\section{The Influence of Service Based on Information Technology Electric Prepaid and Customers Relationship of Customer Trust and Its Impact on The Company Image}

\author{
(A Survey of Electric Customer Services in West Kalimantan)
}

\begin{abstract}
Prepaid Electricity information technology services (LPB) and Customers Relations who have been and services are being implemented by PLN examined in this study does add to the sense of customers' trust that can influencing in increasing the company's image. The study used a survey of 250 customers of prepaid electricity in the province of West Kalimantan. The results using descriptive analysis approach showed that customers information technology services and customer relations, customer trust and corporate image according to the customer is already good. While the approach of verification analysis found that the use of information technology is growing rapidly in support of customer service will greatly help increase customers' trust in the company's products, which leads to improved corporate image.
\end{abstract}

Keywords: Service, information technology electric, customer relationship, company image 


\section{PENDAHULUAN}

Pada tahun 2013 rasio elektrifikasi Kalimantan Barat ditargetkan 78,9\%, sedangkan tahun 2008 realisasi $57,3 \%$, sehingga rasio elektrifikasi Kalimatan Barat mengalami kenaikan dari tahun 2008 sebesar 37,7\%. Hal ini menjadikan Kalimantan Barat termasuk dalam pertumbuhan kelistrikan yang cukup tinggi, sehingga diharapkan pembangunan pembangkit dan jaringan listrik dapat memenuhi kebutuhan listrik yang meningkat pada tahun 2013.

PLN Kalbar, menargetkan jumlah pelanggan baru tahun 2012 mencapai 65 ribu, hal tersebut dilakukan untuk mencapai rasio elektrifikasi di Kalbar di atas 60 persen. Saat ini rasio elektrifikasi di Kalbar baru pada kisaran 30 hingga 50 persen, khususnya pada wilayah perbatasan.

Berdasarkan hasil survey LSI (Lembaga Survei Indonesia) yang dilaksanakan pada tanggal 3-17 Juli 2011 bahwa kualitas layanan PLN walaupun sudah ada Listrik Prabayar memperlihatkan perbaikan layanan yang kurang berarti di mata masyarakat dibanding hasil survey tahun sebelumnya. (sumber: majalah PLN FOKUS, Layanan PLN jalan di tempat?).

Masalah pelayanan pelanggan menjadi krusial dalam hal ini, untuk mengantisipasi rendahnya kepuasan yang masih dirasakan oleh konsumen PLN. Memberikan pelayanan yang terbaik kepada konsumen, dewasa ini sangat memungkinkan tercapai dengan semakin majunya teknologi informasi. PLN berupaya meningkatkan pelayanannya dengan memanfaatkan teknologi informasi tersebut, dengan sistem informasi listrik prabayar.

Pentingnya pelayanan yang baik adalah untuk menumbuhkan kepercayaan. Pelayanan yang diterima oleh pelanggan bisnis, dan komitmen pelanggan merupakan dua konstruk anteseden terhadap kepercayaan pelanggan. (Gounaris, 2005). Selain upaya pelayanan pelanggan yang optimal, dewasa ini hubungan pelanggan atau kerelasian pelanggan menjadi faktor penentu dalam strategi untuk memenangkan pelanggan. Payne, (2000:56).

Pelayanan prima dan kerelasian pelanggan ini pada akhirnya akan berdampak pada citra positif perusahaan Nguyen \& LeBlanc (2002). Sedangkan interaksi antara konsumen dan perusahaan begitu tinggi pada bisnis jasa memberikan pengaruh positif terhadap citra perusahaan. Kim \& Suh (2002). Melalui pelayanan pelanggan dan kerelasian pelanggan yang menimbulkan kepercayaan pelanggan, maka kepercayaan pelanggan pun berkontribusi positif terhadap citra. Heerden \& Puth (1995). Untuk itu perlu dikaji apakah ada pengaruh antara pelayanan teknologi informasi Listrik Prabayar, dan kerelasian pelanggan terhdap Kepercayaan Pelanggan dan dampaknya terhadap Citra Perusahaan PLN.

\section{KAJIAN LITERATUR}

Grand theory dalam penelitian ini adalah strategi pemasaran, di mana menurut Cravens dan Piercy (2006:31) mengemukakan bahwa strategi pemasaran terdiri dari analisis, pengembangan strategi dan implementasi kegiatan dalam pengembangan visi tentang pasar yang menguntungkan organisasi, memilih strategi pasar sasaran, penentuan tujuan dan pengembangan, implementasi serta pengelolaan strategi penempatan program pemasaran yang dirancang untuk memenuhi tuntutan nilai konsumen dalam setiap pasar sasaran.

Pada tataran middle range theory, diaplikasikan teori kegiatan internal perusahaan yang bertujuan customer oriented, yaitu dengan menghadirkan pelayanan yang mampu memberikan nilai dan kepuasan (value and satisfaction) akan kebutuhan pelanggan. Kotler \& Keller (2009:25).

Egan (2001:36) menyebutkan bahwa ikatan dengan konsumen merupakan masalah sentral dalam strategi pemasaran dalam menumbuhkan kepercayaan konsumen. Hal ini dikuatkan oleh Kotler dan Keller (2009:113) bahwa interaksi perusahaan dengan konsumen yang terwujud melalui pelayanan yang prima dan kerelasian pelanggan yang interaktif akan mempengaruhi citra perusahaan secara umum.

\section{Penelitian Terdahulu}

Beberapa hasil penelitian yang berhubungan dengan pelayanan pelanggan, kepercayaan pelanggan, kepercayaan pelanggan dan citra perusahaan, serta hubungan diantaranya. 
Pelayanan yang diterima oleh pelanggan bisnis, dan komitmen pelanggan merupakan dua konstruk anteseden terhadap kepercayaan pelanggan untuk model bisnis ke bisnis (B2B) (Gounaris,2005). Relasi pelayanan pelanggan dengan kepercayaan ini diperkuat dengan hasil penelitian Eisingerich \& Bell (2008), bahwa Pelayanan pelanggan dibedakan menjadi teknikal dan fungsional. Keduanya berperan dalam membangun kepercayaan pelanggan.

Keterkaitan kerelasian pelanggan dan kepercayaan pelanggan didokumentasikan oleh penelitian Schumann (2010) bahwa kepercayaan pelanggan berkaitan erat dengan kerelasian pelanggan. Perbedaan respon kepercayaan pelanggan dalam kerelasian pelanggan dipengaruhi budaya negara setempat. Sehingga building customer trust merupakan hal penting dalam menjalankan bisnis dengan konsumen (Kourdi, 2003).

Kepercayaan pelanggan itu sendiri merupakan anteseden untuk penilaian citra yang baik oleh konsumen. Heerden \& Puth (1995) dalam penelitiannya di Afrika Selatan, bahwa kredibilitas/ satabilitas sebagai ukuran kepercayaan berkontribusi positif terhadap citra bank di Afrika Selatan. Omar et.al. (2009) memperkuat penelitian adanya pengaruh kepercayaan terhadap citra perusahaan. Pelayanan pelanggan dan kerelasian pelanggan selain akan berpengaruh tidak langsung terhadap citra perusahaan, juga dapat memberikan dampak secara langsung. Penelitian Nguyen \& LeBlanc (2002) dan Kim \& Suh (2002), telah membuktikan kedua pengaruh langsung variabel tersebut terhadap citra perusahaan.

\section{Hipotesis}

Pelayananan berbasis Teknologi Informasi Listrik Prabayar, Kerelasian Pelanggan, sudah baik dilaksanakan, Kepercayaan Pelanggan tergolong tinggi dan Citra Perusahaan dinilai baik oleh pelanggan PLN pra bayar di Kalimantan Barat. Terdapat hubungan korelasional antara Pelayanan berbasis Teknologi informasi Listrik Prabayar dan Kerelasian Pelanggan.

Terdapat pengaruh pelayananan berbasis Teknologi Informasi Listrik Prabayar dan Kerelasian Pelanggan terhadap Kepercayaan Pelanggan baik secara parsial maupun secara simultan.
Terdapat pengaruh langsung pelayananan berbasis Teknologi Informasi Listrik Prabayar, Kerelasian Pelanggan terhadap Citra Perusahaan. Terdapat pengaruh Kepercayaan Pelanggan terhadap Citra Perusahaan. Terdapat pengaruh secara tidak langsung pelayananan berbasis Teknologi Informasi Listrik Prabayar terhadap Citra Perusahaan melalui Kepercayaan Pelanggan.

\section{METODE}

Jenis penelitian yang digunakan adalah deskriptif dan verifikatif, sehingga terdapat dua metode survey yang diterapkan yaitu descriptive survey dan explanatory survey. Oleh karena tipe penelitian ini adalah tipe kausalitas, yaitu penelitian yang bersifat sebab akibat pada variabel independen (variabel yang mempengaruhi) dan dependen (yang dipengaruhi).

Jadi jenis investigasi yang dilakukan adalah Kausalitas, sedangkan unit analisisnya adalah Pelanggan listrik. Jenis data yang dikumpulkan merupakan data sekunder dan data primer. Data sekunder didapat dari laporan bulanan yang diterbitkan oleh PLN Kalimantan Barat, sedangkan data primer berupa data hasil survey langsung ke pelanggan listrik yang menjadi sampel penelitian, sebanyak 250 pelanggan.

Kuesioner disebar kepada sampel melalui teknik two stage sampling, di mana unit sampel pertama diambil adalah kota/kabupaten di Kalimantan Barat, selanjutnya diambil sampel kecamatan tiap kota/ kabupaten sebagai unit sampel kedua.

\section{Operasionalisasi Variabel}

Pada pelayanan pelanggan atribut produk itu sendiri menjadi dimensi, mudah didapat (available) X1, nyaman atau enak dikonsumsi (convenience) $\mathrm{X} 2$, dan menarik (attractive) X3, Peter dan Donelly (2003:213). Kerelasian pelanggan (Storbacka dan Lehtinen, 2001:4, 101) dapat diukur diantaranya melalui Customer Value (Nilai) X3, Business case (bisnis) X4, dan Customer strategy (strategi pelanggan) X5.

Selanjutnya Kepercayaan Pelanggan (Customer Trust) berdasar Mitchell \& Lynch, (1988) dapat diukur melalui beberapa dimensi, seperti Integritas (Probity) Y1, Komitmen (Equity) Y2, dan Konsistensi (Reliability) Y3. 
Citra perusahaan menurut Kotler \& Keller, (2009 : 113) dapat diukur melalui Kesan (Impression) Y4, Kepercayaan (Beliefs) Y5 dan Sikap (Attitudes) Y6.

\section{Validitas dan Reliabilitas Instrumen}

Validitas item dilakukan dengan teknin korelasi dari Pearson, antara nila item pernyataan kuesioner dengan nilai total. Hasil korelasi setiap item dalam kuesioner sudah cukup baik, dimana rentang korelasi bernilai 0,38-0,699, jadi sudah melebihi nilai default sebesar 0,3. Azwar (2000).

Uji reliabilitas data penelitian ini menggunakan metode (rumusan) koefisien Alpha Cronbach's. Sekaran, 2006). Patokan yang umumnya telah diterima secara luas adalah bentuk indikator yang mendapat koefisien lebih besar dari 0,7 dinyatakan reliabel, Sekaran (2006). Pelayanan pelanggan bernilai reliabilitas sebesar 0,687, Kerelasian Pelanggan sebesar 0,669, Kepercayaan Pelanggan dan Citra Perusahaan masing-masing sebesar 0,834 dan 0,731.

\section{Analisis Data}

Untuk hipotesis deskriptif digunakan (Hipotesis 1) uji t untuk rata- rata sampel masing-masing variabel, di mana standar yang ditetapkan adalah minimal skor 750 (dari 250 responden, rata-rata responden menghasilkan skor 3). Jadi kinerja variabel disebut sudah baik apabila nilai rata-rata sampel $>$ 750. Hipotesis verifikatif (Hipotesis 2- Hipotesis 6) dibuktikan dengan analisis Structural Equation Modeling (SEM) dengan menggunakan program Lisrel 8.3.

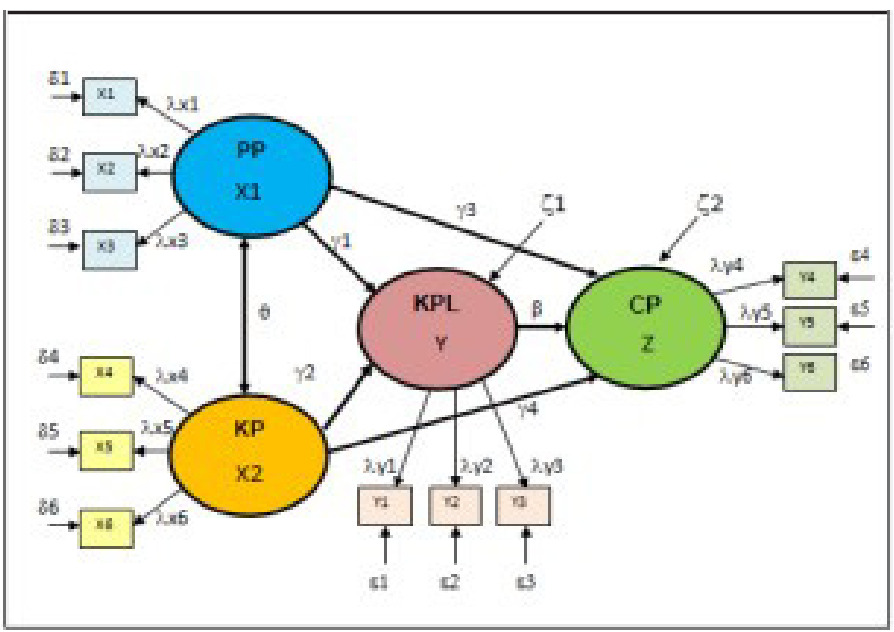

Gambar 1 Model Persamaan Struktur
Keterangan :

$\xi_{1}=$ Pelayanan Pelanggan Teknologi Informasi Listrik Prabayar $=\mathrm{PP}$

$\mathrm{X} 1=$ Kebenaran data tagihan pelanggan

$\mathrm{X} 2=$ Nilai pelanggan

X3 = Sistim hardware jasa listrik prabayar

$\xi_{2}=$ Kerelasian Pelanggan Listrik $=\mathrm{KP}$

$\mathrm{X} 4=$ Value proposition

$\mathrm{X} 5=$ Business case

X6 = Sistim hardware jasa listrik prabayar

$\eta_{1}=$ Kepercayaan Pelanggan $=\mathrm{KPL}$

$\mathrm{Y} 1=$ Integritas

Y2 = Komitmen

Y3 = Konsistensi

$\eta_{2}=$ Citra Perusahaan $=\mathrm{CP}$

Y4 = Kesan

Y5 = Kepercayaan

Y6 = Sikap

$\theta=$ Koefisien korelasi antara variabel eksogen dengan variabel eksogen

$\lambda=$ Koefisien jalur antara baik variabel eksogen maupun endogen dengan sub variabel (indikator)

$\beta=$ Koefisien jalur antara variabel endogen dengan variabel endogen

$\gamma=$ Koefisien jalur antara variabel eksogen dengan variabel endogen.

$\delta=$ Kekeliruan pengukuran untuk subvariabel (indikator) eksogen.

$\varepsilon \quad=$ Kekeliruan pengukuran untuk sub variabel (indicator) endogen.

$\zeta=$ Kekeliruan pengukuran untuk sub variabel laten endogen

\section{HASIL DAN PEMBAHASAN}

Pelayanan Pelanggan, Kerelasian Pelanggan, Kepercayaan Pelanggan dan Citra Perusahaan menurut Pelanggan

Pelanggan sudah merasakan pelayanan pelanggan teknologi informasi listrik prabayar oleh PLN yang dianggap memenuhi harapan. Teknologi informasi dalam pelayanan listrik prabayar akan membuat pelanggan mudah dalam membayar biaya listrik pra bayar karena saat ini sudah banyak terdapat countercounter yang menjual token listrik. Selain itu, al pemakaian listrik pra bayar mudah untuk dikendalikan karena terdapat nominal saldo listrik di meter pra 
bayar yang dapat dilihat langsung oleh pelanggan dan akan berkurang sesuai dengan pemakaian.

Program kerelasian pelanggan oleh PLN dinyatakan memenuhi harapannya terlepas dari adanya kekurangan-kekurangan pada masalah cost, dan hubungan dengan pelanggan. PLN melalui strategi kerelasian pelanggan seperti layanan call center, perluasan outlet pembayaran dan perluasan jaringan ATM, telah dapat memberikan hubungan atau kerelasian yang baik yang dinilai oleh pelanggan. PLN memanfaatkan semua sumberdaya yang dimilikinya agar dapat menunjukkan daya tanggap atau respon yang baik dengan inovasi-inovasi layanan yang diberikan dari dalam kerelasian pelanggan.

PLN dapat memenuhi kepercayaan pelanggan oleh karena pada dasarnya konsumen sudah mendapatkan fitur-fitur listrik prabayar yang memenuhi kriteria pelanggan. Seperti integritas petugas, komitmen petugas dan konsistensi dalam penyelesaian masalah. Masalah yang ditemui di lapangan tidak menjadikan pelanggan hilang kepercayaan terhadap PLN, karena masalah teknis atau gangguan teknis biasanya dapat diatasi dengan baik, walaupun waktu penyelesaian dirasakan kurang baik oleh pelanggan.

Hasil survey menunjukkan bahwa citra perusahaan PLN itu sudah baik. Hal ini disebabkan atribut produk itu sendiri yang mudah digunakan, memberikan kemudahan variasi pembayaran kepada pelanggan dan juga pelayanan petugas yang cukup baik. Sehingga kesan pelanggan terhadap listrik prabayar ini baik dan menimbulkan keyakinan pelanggan terhadap PLN serta sikap pelanggan yang baik pula.

\section{Pengaruh Pelayanan Pelanggan, dan Kerelasian Pelanggan terhadap Kepercayaan Serta Dampaknya terhadap Citra Perusahaan}

Hasil analisis melalui Lisrel 8.3, indeks kecocokan model dengan uji chi kuadrat menunjukkan nilai chi kuadrat dengan nilai signifikansi ( $p$-value) sebesar 0,52 . Hal ini menunjukkan bahwa model fit dengan data. Namun demikian nilai kecocokan chi kuadrat tidak dapat dijadikan satu-satunya ukuran kecocokan model, terdapat indeks kecocokan Goodness of Fit (GFI) dan Adjusted GFI (AGFI), di mana nilai GFI > 0,9 menunjukkan nilai kecocokan yang baik. Model kausal penelitian menghasilkan nilai GFI dan AGFI masing-masing sebesar 0,97 dan 0,95, yang berarti kecocokan model sangat baik. $\mathrm{CFI}>0,9$ menunjukkan kecocokan yang baik dan nilai CFI model penelitian memenuhi persayaratan kecocokan CFI yaitu sebesar 1,00. Sehingga dapat dikatakan kecocokan model dengan data adalah sangat baik.

Sementara itu hasil model pengukuran :

Ketersediaan (X11) dan kenyamanan (X12) merupakan dua indikator Pelayanan Pelanggan yang memiliki bobot koefisien paling besar yaitu 0,41 dan 0,43 sementara ketertarikan (X13) bobot koefisiennya paling kecil yaitu sebesar 0,23 .

Nilai pelanggan (X21) merupakan indikator dengan bobot paling tinggi yaitu sebesar 0,64. Business case (X22) dan customer strategy (X23) merupakan dua indikator Pelayanan Pelanggan yang memiliki bobot rendah yaitu 0,45 dan 0,48 .

Integritas (Y11) merupakan indikator dengan bobot paling tinggi yaitu sebesar 0,86 . Komitmen (Y12) dan Konsistensi (X23) merupakan dua indikator Pelayanan Pelanggan yang memiliki bobot rendah yaitu 0,82 dan 0,81 . Sehingga integritas merupakan indikator yang paling dipentingkan oleh pelanggan dalam menumbuhkan kepercayaan.

Indikator citra perusahaan terlihat relatif sama dalam bobotnya. (Y21) merupakan indikator dengan bobot paling tinggi yaitu sebesar 0,77. Customer beleifs (Y22) dan Attitudes (Y23) merupakan dua indikator Citra yang memiliki bobot relatif rendah yaitu 0,73 dan 0,72 .

Berdasarkan pengujian model struktural, diketahui bahwa besaran pengaruh Pelayanan Pelanggan (PP) terhadap Kepercayaan Pelanggan (KPL) adalah 0,78, sedangkan pengaruh Kerelasian Pelanggan (KP) terhadap Kepercayaan Pelanggan (KPL) sebesar 0,11 (tidak signifikan). Variabel Citra institusi (CP) dipengaruhi oleh PP sebesar 0,46, dipengaruhi oleh Cp sebesar 0,97, dan dipengaruhi oleh KP sebesar 0,33 .

\section{Korelasi Pelayanan Pelanggan dan Kerelasian Pelanggan}

Hasil korelasi sebesar 0,80 dinyatakan signifikan. Sehingga pelayanan pelanggan sebagai bagian dari 
bisnis berkaitan erat dengan pengaturan hubungan dengan konsumen (kerelasian pelanggan) dengan cara melakukan tindakan secara nyata dan terus menerus untuk menciptakan, mempertahankan dan meningkatkan hubungan dengan konsumen sebagai bagian dari suatu proses pemasaran.

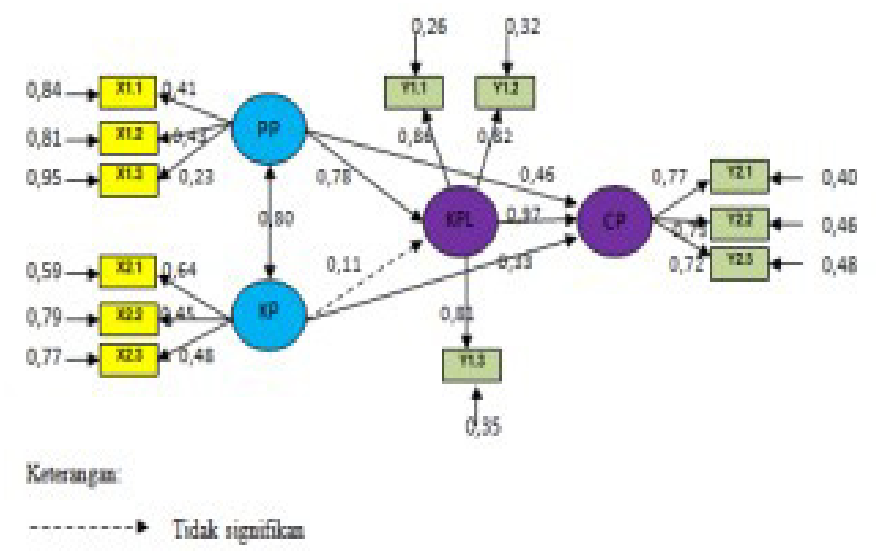

Gambar 2 Penaksiran Koefisien Model Secara Lengkap

Hasil uji signifikansi koefisien model struktural adalah sebagai berikut :

Tabel 1 Persamaan Struktural Hasil Perhitungan

\begin{tabular}{ccccc}
\hline \multirow{2}{*}{ Konstruk Endogen } & \multicolumn{3}{c}{ Konstruk Eksogen } & \multirow{2}{*}{ Error } \\
\cline { 2 - 4 } & 0.1 & 0.112 & [1 & \\
\hline \multirow{2}{*}{ 回2 } & 0.78 & 0.11 & 0.26 \\
& $(5.32)$ & $(0.61)$ & & \\
& 0.46 & 0.31 & 0.97 & 0.06 \\
& $(9.11)$ & $(6.43)$ & $(2.47)$ & \\
\hline
\end{tabular}

Keterangan:

- nilai dalam kurung adalah t hitung

- Signifikan bila $t>1,96$

Pengaruh Pelayananan Berbasis Teknologi Informasi Listrik Prabayar dan Kerelasian Pelanggan terhadap Kepercayaan Pelanggan

Pelayanan Pelanggan signifikan berpengaruh terhadap Kepercayaan Pelanggan (Tabel 1). Sehingga, pelayanan yang konsisten kepada pelanggan yaitu dengan menghadirkan pengalaman pelayanan yang berkualitas serta sepanjang waktu, merupakan aspek penting dalam menciptakan hubungan kepercayaan dengan pelanggan. Sesuai penelitian Kourdi (2003). Berdasarkan Gambar 2, dengan besaran pengaruh yang relatif kecil, Kerelasian Pelanggan tidak memberikan pengaruh yang signifikan terhadap Kepercayaan Pelanggan. (Tabel 1). Pelanggan belum dapat merasakan kemudahan dari program yang dapat berhubungan langsung dengan pelanggan seperti teknologi terintegrasi yang menghubungkan secara personal dari pelanggan kepada layanan PLN. Yung Shao Yeh \& Yung Ming Li (2009) menyebutkan bahwa hubungan pelanggan adalah upaya untuk menyediakan pendekatan terintegrasi terhadap semua aspek pada perusahaan dalam kaitannya dengan pelanggan yang meliputi marketing, sales dan support.

\section{Pengaruh Pelayananan Berbasis Teknologi Informasi Listrik Prabayar dan Kerelasian Pelanggan terhadap Citra Perusahaan}

Koefisien pengaruh Pelayanan Pelanggan (X1) dan Kerelasian Pelanggan (X2) terhadap Citra Perusahaan (Y2) masing-masing bernilai positif, yaitu 0,46 dan 0,33. Sedangkan dari uji signifikansi juga positif. (Tabel 1).

Pelayanan Pelanggan yang disajikan secara baik dan konsekuen dalam kualitasnya, dapat membentuk citra positif perusahaan terhadap konsumen. Hal ini sejalan dengan Keller (1993) seperti yang dikutip oleh Andreassen dan Lindstead (1998) bahwa pada tingkat perusahaan, citra dapat diartikan sebagai persepsi suatu organisasi yang tercermin berupa asosiasi dalam ingatan konsumen.

Ikatan dengan konsumen (kerelasian), yang merupakan bagian dari suatu hubungan di mana kedua pihak membentuk suatu kesatuan untuk mencapai tujuan. Hollensen (2003:211). Sehingga citra perusahaan yang diinginkan dapat dicapai.

\section{Pengaruh Kepercayaan Pelanggan terhadap Citra Perusahaan}

Koefisien pengaruh Kepercayaan Pelanggan (Y1) terhadap Citra Perusahaan (Y1) bernilai positif, yaitu 0,97 . Dari hasil pengujian adalah signifikan (Tabel 1). Nguyen dan LeBlanc (2002) menyatakan bahwa citra institusi adalah gambaran keseluruhan dalam benak masyarakat mengenai suatu organisasi. Citra institusi ini berkaitan dengan aspek emosional yaitu dengan dimensi-dimensi psikologis yang dimanifestasikan dalam bentuk perasaan dan sikap terhadap suatu organisasi. Perasaan ini tidak akan terjadi tanpa adanya pengalaman individu dengan suatu organisasi. Kepercayaan Pelanggan dalam hal ini merupakan 
pengalaman pelanggan.

Pengaruh Tidak Langsung Pelayananan Berbasis Teknologi Informasi Listrik Prabayar terhadap Citra Perusahaan melalui Kepercayaan Pelanggan

Koefisien pengaruh Pelayanan Pelanggan terhadap Kepercayaan Pelanggan (X2) dan Kepercayaan Pelanggan (X2) terhadap Citra Perusahaan (Y2) masing-masing bernilai positif, yaitu 0,78 dan 0,97 . Dengan nilai $t$ masing-masing hasil uji terdahulu adalah 5,32 dan 2,41. Oleh karena itu Pelayanan Pelanggan berpengaruh secara tidak langsung terhadap Citra Perusahaan melalui Kepercayaan Pelanggan. Sementara koefisien pengaruh Kerelasian Pelanggan (X1) terhadap Kepercayaan Pelanggan (X2) tidak signifikan, walaupun Kepercayaan Pelanggan (X2) terhadap Citra Perusahaan (Y2) signifikan. Oleh karena itu Kerelasian Pelanggan tidak berpengaruh secara tidak langsung terhadap Citra Perusahaan melalui Kepercayaan Pelanggan.

Nykamp (2001:6) menyebutkan bahwa suatu perusahaan tidak dapat menjalin suatu hubungan dengan pelanggan kecuali perusahaan tersebut memahami mereka. Kurangnya program interaksi antara PLN dengan pelanggan, menyebabkan tidak adanya hubungan dengan kepercayaan pelanggan. Sementara itu interaksi merupakan komponen penting bagi setiap inisiatif Customer Relationship Management.

\section{SIMPULAN}

Tingkat pelaksanaan pelayanan teknologi informasi pelanggan dan kerelasian pelanggan terhadap kepercayaan pelanggan dan citra perusahaan menurut pelanggan adalah sudah baik. Terdapat hubungan positif Pelayanan pelanggan berbasis teknologi informasi Listrik Prabayar dengan Kerelasian pelanggan. Pelayanan Pelanggan memberikan pengaruh yang penting terhadap Kepercayaan Pelanggan, sedangkan tidak adanya pengaruh kerelasian pelanggan berarti program hubungan dengan pelanggan yang diupayakan oleh PLN, belum menyentuh aspek pribadi pelanggan sehingga tidak menimbulkan kepercayaan.

Upaya penciptaan dan penambahan nilai bagi pelanggan dapat dituangkan dalam suatu bentuk pelayanan pelanggan (customer service) yang merupakan bagian dari kepedulian pada pelanggan (customer care). Upaya kepedulian terjadap pelanggan melalui pelayanan yang prima, akan membentuk citra perusahaan di benak konsumen. Terdapat pengaruh Kepercayaan Pelanggan terhadap Citra Perusahaan. Citra institusi ini berkaitan denganaspek emosional. Perasaan ini tidak akan terjadi tanpa adanya pengalaman individu dengan suatu organisasi.

Kepercayaan Pelanggan dalam hal ini merupakan pengalaman pelanggan. Pelayanan melalui kepercayaan pelanggan berpengaruh terhadap citra perusahaan, sedangkan kerelasian pelanggan melalui kepercayaan pelanggan tidak berpengaruh terhadap citra perusahaan. Kurangnya program interaksi antara PLN dengan pelanggan, menyebabkan tidak adanya hubungan dengan kepercayaan pelanggan yang berdampak pada tidak ada pengaruhnya terhadap citra perusahaan.

\section{Saran}

Saran untuk implementasi yaitu pertama, perlunya strategi dalam pelayanan pelanggan yang meliputi perluasan jaringan outlet pembelian listrik, perbaikan sistem informasi control pemakaian dan interaksi konsumen dengan PLN, perluasan pembayaran melalui ATM. Kedua, peningkatan program kerelasian pelanggan seperti, perluasan lini harga listrik prabayar, pelatihan terhadap petugas pelayanan sehingga memahami SOP pelayanan dengan baik, perbaikan sistem IT untuk secara interaktif. Ketiga, peningkatan kepercayaan pelanggan meliputi pelatihan service quality bagi petugas pelayanan, penambahan petugas satuang cepat tanggap terhadap gangguan.

Saran untuk pengembangan ilmiah yaitu perlu adanya penelitian yang lebih luas dengan memperhitungan faktor sosiologis dan demografis. Sehingga dapat diupayakan program pelayanan yang cepat tanggap sesuai kondisi sosial dan demografi para pelanggan. Selain itu, perlu diupayakan penelitian eksploratif mengenai pelayanan, kerelasian pelanggan dan kepercayaan pelanggan serta citra perusahaan, khusus untuk pelayanan yang dilakukan PLN sehingga dapat dipetakan indikator- indikator pemasaran yang penting pada objek pelanggan/konsumen kelistrikan. 


\section{DAFTAR PUSTAKA}

Andreassen, W., \& Lindestad, B. (1998). Customer Loyalty and Complex Service The Impact of Corporate Image on Quality, Customer Satisfaction and Loyalty for Customers With Varying Degrees of Service Expectise. International Journal of Srvice Industry Management, Vol 9. Iss.1.

Azwar, \& Saifuddin, (2000). Reliabilitas dan Validitas, Yogyakarta : Pustaka Belajar.

Cravens, David, W., Piercy, \& Nigel, F. (2006). Strategic Marketing. International Edition, McGraw-Hill.

Egan, \& John. (2001). Relationships Marketing: Exploring Relational Strategies in Marketing. Pearson Education Limited.

Eisingerich, Andreas B., Simon, J., \& Bell. (2008). Perceived Service Quality and Customer Trust Does Enhancing Customers' Service Knowledge Matter?. Journal of Service Research, vol. 10 no. 3.

Gounaris, \& Spiros P. (2005). Trust And Commitment Influences On Customer Retention: Insights From Business- To-Business Services. Journal of Business Research, Volume 58, Issue 2.

Heerden, C. H., \& Puth, G. (1995). Factors that determine the corporate image of South African banking institutions: an exploratory investigation. International Journal of Bank Marketing, Vol. 13 No.3. Hollensen.

Svend. (2003). Marketing Management A Relationship Approach. Pearson Education Limited-Prentice Hall, New Jersey.

Kim, Chung H., \& Taewon, S. (2002). Consumers' Multilayered Experience and Their Perception of Corporate Image, American Marketing Conference.
Kotler, Phillip, Keller, \& Kevin, L. (2009). Marketing Management. Pearson Prentice Hall, 13th Edition.

Kourdi, \& Jeremy, (2003). Building Customer Trust And Loyalty. Journal of Financial Services Marketing 7. 3.

Mitchell, P., Reast, J., \& Lynch, J. (1998). Exploring the Foundations of Trust. Journal of Marketing Management, 14: 159-172.

Nguyen, Nha, \& Gaston, L. (2002). The Mediating Role of Corporate Image on Customers Retention Decisions : An Investigation in Financial Services. The International Journal of Banking Marketing, Vol.16, Iss.2.

Nykamp, \& Melinda. (2001). The Customer Differential : The Complete Guide to Implementing Customer Relationship Management. American Management Association. New York.

Omar, M., Williams, R. L., \& Jr, Lingelbach, D. (2009). Global brand market-entry strategy to manage corporate reputation. Journal of Product \& Brand Management, Vol. 18 No.3.

Payne, \& Adrian. (2000). Pemasaran Jasa. Edisi Pertama, Yogyakarta, ANDI.

Peter, J. P., \& J.H. Donnelly, Jr. (2003). A Preface to Marketing Management, Nineth Edition, Boston: McGraw-Hill. Schumann, Jan H. (2010), Drivers of Trust in Relational Service Exchange: Understanding the Importance of Cross-Cultural Differences. Journal of Service Research November vol. 13 no. 4.

Sekaran, \& Uma. (2006). Research Methods For Business Buku 2. Edisi Bahasa Indonesia 4, Salemba Empat, Jakarta.

Shao, Y., \& Yung, M. L. (2009). Building trust in m-commerce : Contribution from Quality and Satisfaction. Online Information Review, Vol. 33 Iss: 6. 
Storbacka, Kaj, J. R., \& Lehtinen, (2001). Customer Relationship Management Creating Competitive Advantage through Win-Win Relationship Strategies. McGrawHill. 